\title{
Island Biogeographic Theory and Conservation Practice: Species-Area or Specious-Area Relationships?
}

\author{
William J. Boecklen* \& Nicholas J. Gotelli \\ Department of Biological Science, Florida State University, \\ Tallahassee, Florida 32306, USA
}

\begin{abstract}
We present statistical techniques to evaluate species-area regressions and models of faunal and floral collapse and apply these techniques to several recent examples from the literature. The application of these models to the design of nature reserves is unwarranted. These models have low explanatory power; they typically explain only half the variation in species number. Their parameter estimates are sensitive to particular cases. Consequently, estimates from these models range over several orders of magnitude following the deletion of a single observation. Species-area and faunal collapse models give unreliable estimates; $95 \%$ prediction intervals and inverse prediction intervals routinely span two or more orders of magnitude. These models should be subordinate to autecological considerations in policy formulation.
\end{abstract}

\section{INTRODUCTION}

Theoretical ecologists have offered species-area relationships and models of faunal collapse as analytical tools to aid conservation biologists in preserving species diversity. Species-area relationships, modelled as linear regressions, can estimate average species number for a given area, or, conversely, the minimum area sufficient to preserve a given number of species. Estimates from these regressions have motivated specific

* Present address: Department of Biological Sciences, Northern Arizona University, Flagstaff, Arizona, 86011, USA.

63

Biol. Conserv. 0006-3207/84/\$03.00 ("Elsevier Applied Science Publishers Ltd. England. 1984. Printed in Great Britain 
recommendations concerning optimal refuge size (Diamond, 1975; Diamond \& May, 1976). Models of faunal and floral collapse are derived directly from equilibrium theory (MacArthur \& Wilson, 1967) and forecast the efficiency of reserves in preserving species number following insularisation (Diamond, 1972; Terborgh, 1974; Soulé et al., 1979; Wilcox, 1980). Predictions from these models have been used to advance management policy (Soulé et al., 1979) and inter-island transfers of endangered species (Temple, 1981).

The suitability of species-area regressions and models of faunal collapse for conservation practice will depend upon the quality of the predictions that they generate. These models could be evaluated through implementation in test situations but the possibility of unforeseen, undesirable, and irrevocable consequences negates this approach with real reserves. Alternatively, statistical analysis is possible. A statistical examination can quantify the level of reliability and precision of these models. We believe that these models should be subjected to a critical statistical examination before conservation policies derived from island biogeographic theory become widespread.

Here, we present statistical techniques to evaluate species-area and faunal collapse models and apply these techniques to several recent examples from the literature. Species-area relationships and the coefficients of faunal collapse models are typically estimated by linear regression. Therefore, we will evaluate these models according to three criteria that are commonly used to evaluate any regression model: $\mathbf{R}$ squared adjusted (the percent variation in species number that is explained by area), sensitivity of the parameter estimates to influential cases, and, most important for conservation practice, the precision of the estimates.

\section{METHODS AND RESULTS}

We selected examples from the literature directed toward conservation practice that presented species counts and areas (Galli et al., 1976; Ward \& Lakhani, 1977; Soulé et al., 1979; Kitchener et al., 1980a,b; Shreeve \& Mason, 1980; Western \& Ssemakula, 1981). Regressions were computed using MINITAB, version 2.0, on the CDC Cyber 730, at the Florida State University Computing Center. The computational forms for the influence functions and prediction intervals follow Weisberg (1980). The 
computational forms for the inverse prediction intervals are from Sokal \& Rohlf (1969).

In some cases, our regression coefficients do not match those published by the original authors. The discrepancies may be due to unreported omissions of anomalous cases by the original authors. We address the performance of these models, not specific values for regression coefficients or point estimates. Therefore, minor changes in the data will not significantly affect our results, nor alter our conclusions.

\section{Explanatory power of area}

The species-area relationship is at least partly epiphenomenal; area is confounded with many variables, such as habitat diversity and resource availability, that may interact and influence species diversity (Connor \& McCoy, 1979). Consequently, the explanatory power of species-area regressions may depend on the degree of multicolinearity between area and these subjacent variables. If area is highly correlated with one subset of these variables but only weakly correlated with another subset, then the explanatory power of area may be of limited utility for conservation recommendations. On the other hand, if area faithfully represents these underlying variables, then area could be a powerful predictor of species diversity.

The coefficient of determination gives the proportion of variability in species number that is explained by regression on area. It is defined as

$$
\mathrm{R}^{2}=1-\mathrm{SSreg} / \mathrm{SYY}
$$

where, SSreg is the sum of squares due to regression, and SYY is the total sum of squares. Weisberg (1980) presents a modified version of the coefficient of determination that corrects for the number of parameters in the model and the number of observations. R-squared adjusted is defined as

$$
\mathbf{R}^{2} \operatorname{adj}=1-[(n-1) /(n-p)]\left[1-R^{2}\right]
$$

where, $\mathrm{n}$ is the number of observations, and $\mathrm{p}$ is the number of parameters in the model. Simple regressions of species number on area have two parameters, slope and intercept. The higher the value of $R^{2}$ or $R^{2}$ adj, the closer is the fit of the data to a linear model.

The determination of an acceptable value for $R^{2}$ or $R^{2}$ adj should depend upon the priority the estimates will be given in policy formulation. 


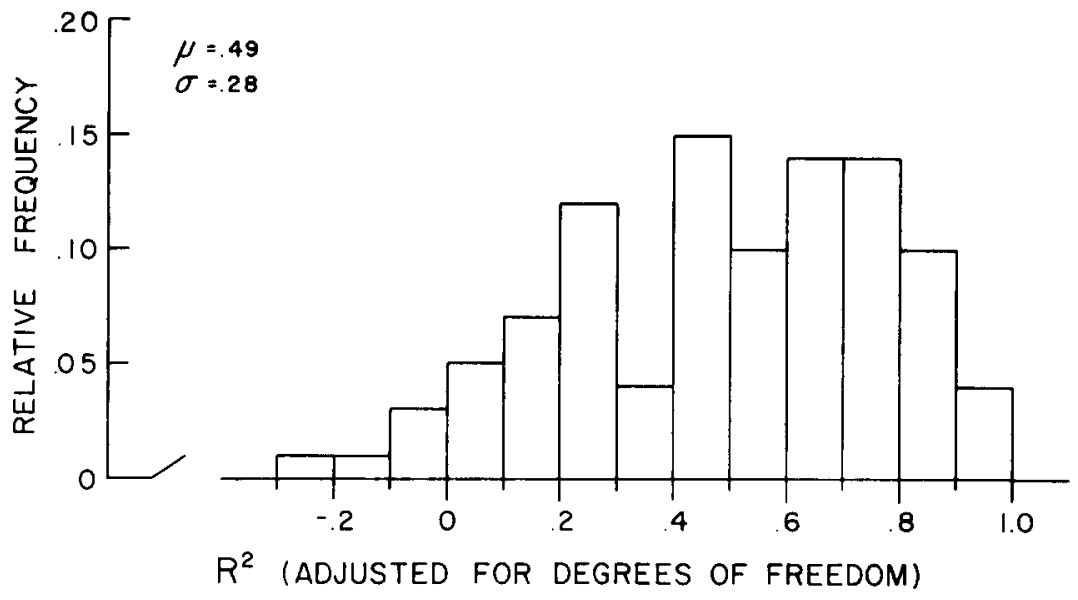

Fig. 1. Frequency histogram of the percent variation in species number explained by regression on area $\left(R^{2}\right.$ adj) for the $100 \log$ - log models in Connor \& McCoy (1979). $\mu$ is the mean, $\sigma$ the standard deviation.

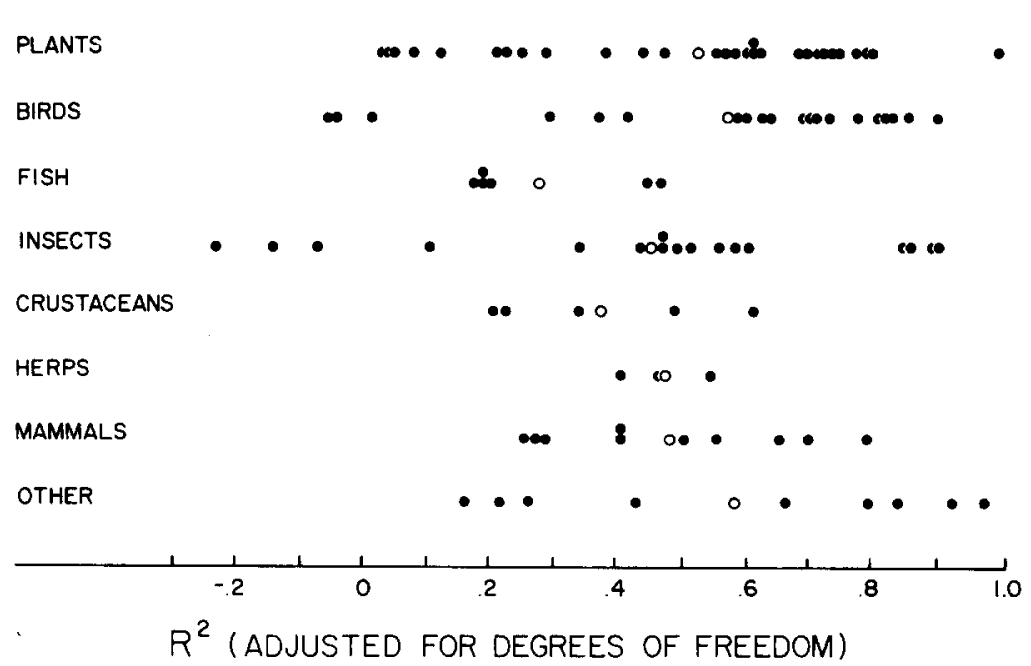

Fig. 2. Data from Fig. 1 partitioned into taxonomic groups. Open circles are the means for each group. 
If the estimate from a species-area regression is the primary consideration in adopting a particular conservation strategy, then a high value for $R^{2}$ adj will be necessary ( 0.70 seems reasonable). On the other hand, if the estimate is a secondary consideration, then a lower value for $\mathbf{R}^{2}$ adj may be acceptable.

We present the $100 \log -\log$ species-area regressions published in Connor \& McCoy (1979) as a general assay of the explanatory power of area. On average, these models explain slightly less than half the variation in species number $\left(\mathrm{R}^{2}\right.$ adj; mean $=0.49$, standard deviation $\left.=0.28\right)$. In addition, only about $30 \%$ of the models have values of $R^{2}$ adj greater than 0.70 , and only $5 \%$ have values greater than 0.90 (Fig. 1). The eleven models selected from the literature for further analysis have a mean $R^{2}$ adj of 0.54 and $45 \%$ of them have $R^{2}$ adj's greater than 0.70 (Table 1 ).

To determine if the species-area relationship is better suited to some taxa, we present the $100 \log -\log$ models from Connor \& McCoy (1979) partitioned into taxonomic groups (Fig. 2). The model appears best suited to plants and birds and most poorly suited to reptiles and amphibians, crustaceans, fish, and insects. However, the performance of the model is unimpressive for all taxa.

The inconsistent performance of these models in explaining the variation in species number suggests that the determinants of species diversity are often too complex to be modelled by area alone. The

TABLE 1

The Percent Variation in Species Number explained by Regression on Area $\left(R^{2}\right.$ adj) for All Models. The Taxon $K$ represents Extinction Coefficients

\begin{tabular}{lll}
\hline \multicolumn{1}{c}{ Author } & \multicolumn{1}{c}{ Taxon } & $R^{2}$ adj \\
\hline Galli et al. (1976) & Birds & 0.910 \\
Kitchener et al. $(1980 a)$ & Lizards & 0.468 \\
Kitchener et al. (1980h) & Mammals & 0.700 \\
Shreeve \& Mason (1980) & Butterflies & 0.417 \\
Soulé et al. (1979) & K1 & 0.072 \\
& K2 & 0.260 \\
& K3 & 0.305 \\
Terborgh (1974) & K4 & 0.290 \\
Ward \& Lakhani (1977) & K & 0.715 \\
Western \& Ssemakula (1981) & Arthropods & 0.763 \\
\hline
\end{tabular}


incorporation of other variables such as a measure of habitat heterogeneity or resource availability may be necessary.

\section{Sensitivity of parameter estimates to influential cases}

Each observation in a regression influences the estimation of the slope and intercept. However, all observations do not have equal weight; points that are far removed from the average species number or the average area may have inordinate influence. The observations in species-area regressions frequently span several orders of magnitude. These models may be especially sensitive to influential cases even when the data are logtransformed. For example, Johnson \& Simberloff (1974) analyse the number of plant species in the British Isles and conclude that habitat heterogeneity, as measured by the number of soil types, is an important predictor of species diversity. McCoy \& Connor (1976) reanalyse these data excluding Britain, a large outlier, and overturn the previous conclusions. Estimates from models that are heavily influenced by one or two observations may be too unreliable for conservation recommendations.

Weisberg (1980) suggests influence functions as an empirical technique to identify influential cases. Influence functions are calculated by deleting the i'th case and recomputing the slope and intercept for the remaining $n-1$ cases. A plot of these recomputed estimates can reveal influential points. It is not necessary to compute $\mathrm{n}$ separate regressions; formulas for the intercept and slope estimates following the deletion of the $i$ 'th case are given in Appendix la.

We present influence functions for Kitchener et al's (1980a) species-area regression of Australian lizards (Fig. 3a) and Kitchener et al.'s (1980b) species-area regression of Australian mammals (Fig. 3b). For the lizards, the slope estimate varies from 4.16 to 5.76 and the intercept estimate from 0.96 to $5 \cdot 20$. Consequently, their point estimate (the minimum area required to preserve all 45 species) varies from $44.2 \times 10^{6}$ to $3.7 \times 10^{9}$ ha following the deletion of a single observation. This range encompasses areas equivalent to Texas and the African continent. The parameter estimates for the mammals, a log-log model, are not as variable; the slope ranges from 0.35 to 0.42 and the intercept ranges from -0.48 to -0.29 . Nevertheless, their point estimate (the minimum area required to preserve all 25 species) still varies from 30000 


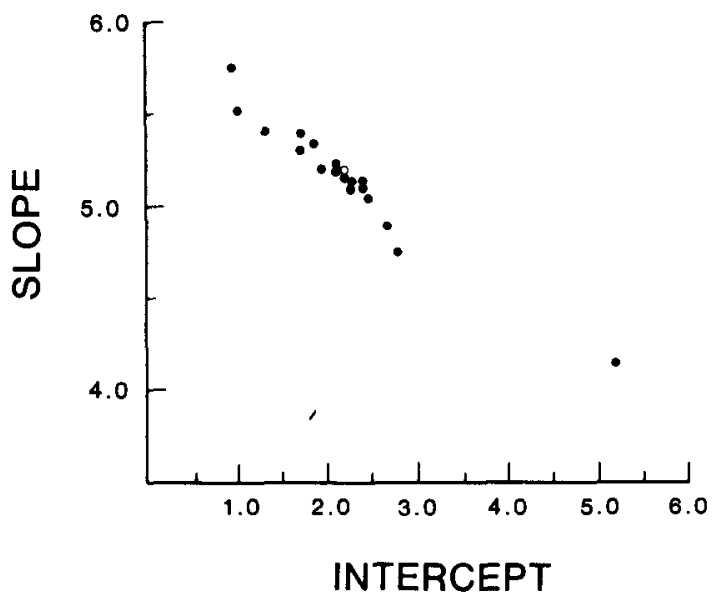

(a)

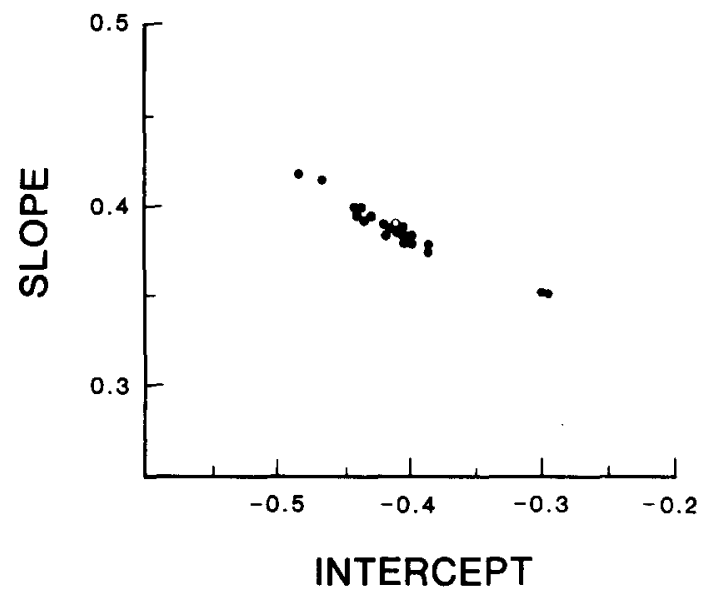

(b)

Fig. 3. (a) Influence functions for the species-area regressions for Australian lizards and (b) Australian mammals. Each point represents the recomputed slope and intercept estimates following the deletion of a single observation. The open circles indicate the position of the slope and intercept estimates for the full data set. Data from Kitchener $e t$ al. $(1980 a, b)$.

to 66000 ha. The ranges of the parameter estimates for the remaining examples from the literature are similar (Table 2).

The sensitivity of these models to peculiar cases supports the contention that the determinants of species diversity are modelled inadequately by area alone and suggests that point estimates derived from these models may be unreliable. 


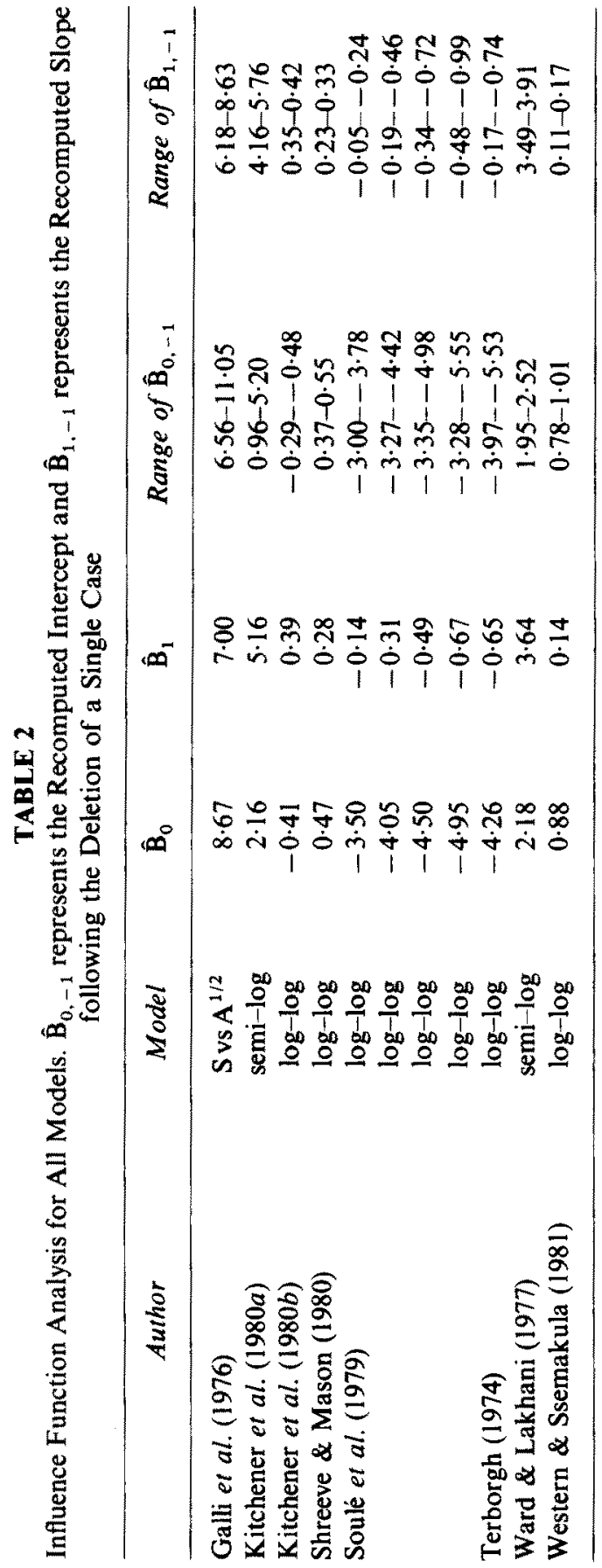




\section{Precision of point estimates}

The precision of point estimates directly measures the suitability of a given model to a particular application. |Models that generate imprecise estimates are sufficient to illustrate general principles but insufficient to warrant specific recommendations. For example, species-area models that generate imprecise estimates can support the observation that species number increases with area but they cannot reliably determine area requirements for a given number of species.

The precision of point estimates derived from species-area regressions will depend upon the explanatory power of area, but it will also depend upon the nature of the point estimate itself. The further a point estimate is removed from the average values of species number and area, the less precise is the estimate. Sampling variation in the slope estimate effectively causes the regression line to pivot on the average values of species number and area (Haas, 1975). The magnitude of the vertical deflection increases as distance from the average increases.

Extrapolations are point estimates completely removed from the data; their precision is especially influenced by variation in the slope estimate. In addition, it is necessary to assume that the species-area relationship remains linear out to the point estimate. However, the best-fitting functional form of the species-area relationship may depend upon the range of areas examined (Preston, 1962; Haas, 1975; Diamond \& Mayr, 1976; Connor \& McCoy, 1979; Gilbert, 1980). For example, a semi-log model may be most appropriate for small values of area, a log-log model for larger areas. Therefore, extrapolation is both biologically and statistically unreliable and the performance of a nature reserve based on an extrapolation is completely uncertain.

A confidence interval establishes boundary points within which the mean species number for a given area will lie with a specified level of confidence, $(1-\alpha) \times 100 \%$. This does not mean that a particular $95 \%$ confidence interval will contain the true mean value $95 \%$ of the time. It does mean that for repeated samples of the same size $95 \%$ of the confidence intervals so constructed will contain the true mean. A simultaneous confidence interval should be used when more than one estimate is made from a single regression. The formulas for confidence intervals are given in Appendix 1(b).

Prediction intervals differ from confidence intervals by establishing boundary points within which a particular species number, not the 


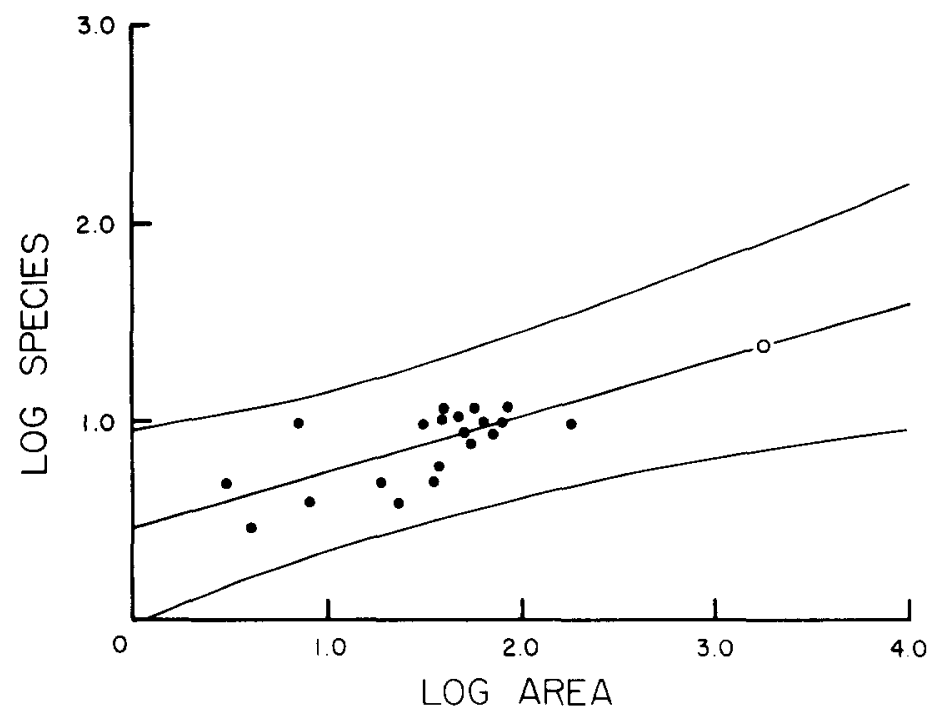

(a)

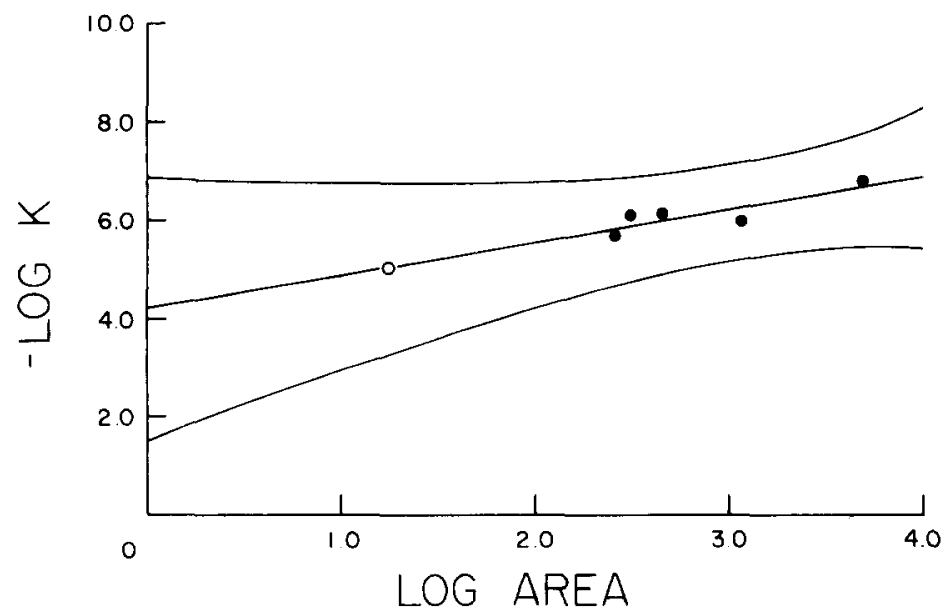

(b)

Fig. 4. (a) Species-area regression for the number of butterflies in woodlands and (b) Terborgh's (1974) estimation of the extinction coefficient, K, for the land birds on BarroColorado Island. The curved lines are $95 \%$ simultaneous prediction intervals. The open circles are the point estimates. Data from Shreeve \& Mason (1980) and Terborgh (1974). 
average species number, for a given area will lie with a specified level of confidence. Prediction intervals may be more appropriate to conservation practice since the number of species a particular area will contain, not the average number of species reserves of a given area will contain, is estimated. Prediction intervals are typically wider than confidence intervals. The formulas for prediction intervals are given in Appendix 1(c).

In conservation practice, the area required to preserve a given number of species is often estimated (Ward \& Lakhani, 1977; Kitchener et al., $1980 a, b ;$ Shreeve \& Mason, 1980). The precision of these estimates can be measured by inverse-prediction intervals. Unlike confidence and prediction intervals for species number, inverse prediction intervals are not symmetric about the point estimate. Formulas for the upper and lower bounds for this interval are given in Appendix 1(d).

We present Shreeve \& Mason's (1980) species-area regression for the number of butterfly species in woodlands (Fig. 4a) and Terborgh's (1974) estimation of the extinction coefficient, $\mathrm{K}$, for Barro-Colorado Island (Fig. 4b) to illustrate the level of precision characteristic of these models. In both cases, the point estimate is more than an order of magnitude removed from the data and the $95 \%$ simultaneous prediction interval spans two or more orders of magnitude at the point estimate. Simultaneous prediction intervals and inverse prediction intervals for the selected literature examples are given in Table 3 . The performance of these models is not impressive. For example, the $95 \%$ inverse prediction interval for Shreeve \& Mason's point estimate spans over two orders of magnitude. The $95 \%$ simultaneous prediction interval for Soule et al.'s (1979) estimate of the extinction coefficient for the Nairobi National Park spans a spectacular 10 orders of magnitude $\left(3 \cdot 6 \times 10^{-12}\right.$ to $\left.6 \cdot 1 \times 10^{-2}\right)$ ! Soule et al. use the point estimate, $4.7 \times 10^{-7}$, to model the faunal collapse of the Nairobi reserve following insularisation. A $95 \%$ simultaneous prediction interval for their Model 4 can be calculated by substituting $3.6 \times 10^{-12}$ and then $6.1 \times 10^{-2}$, the upper and lower bounds of the $95 \%$ simultaneous prediction interval for the point estimate, into their model. The resulting forecast warns that the Nairobi reserve will lose between $0.5 \%$ and $99.5 \%$ of its species in 5000 years with a $95 \%$ level of confidence (Fig. 5)!

The level of precision demonstrated by these models is obviously insufficient to warrant specific conservation recommendations. Two possible exceptions are the models of Western \& Ssemakula (1981) and 


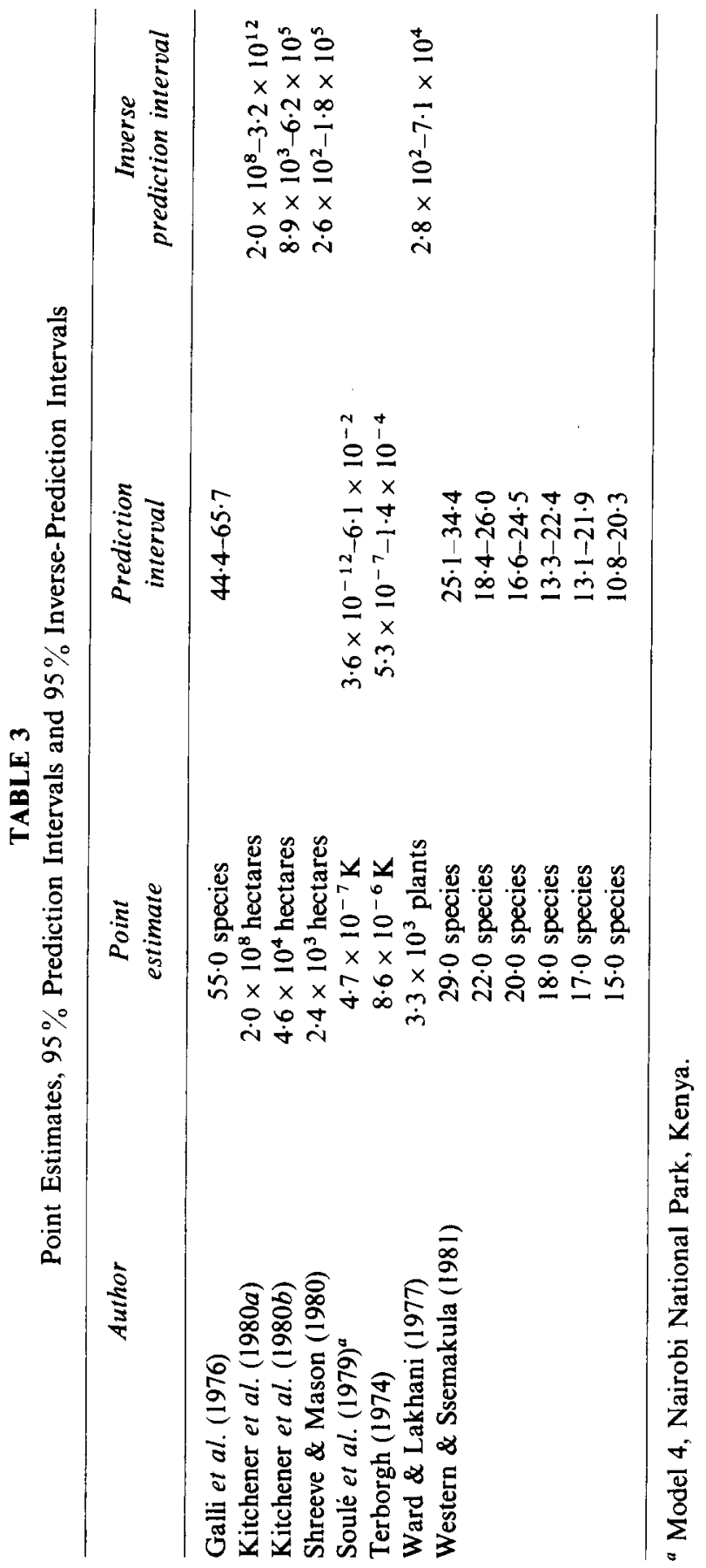




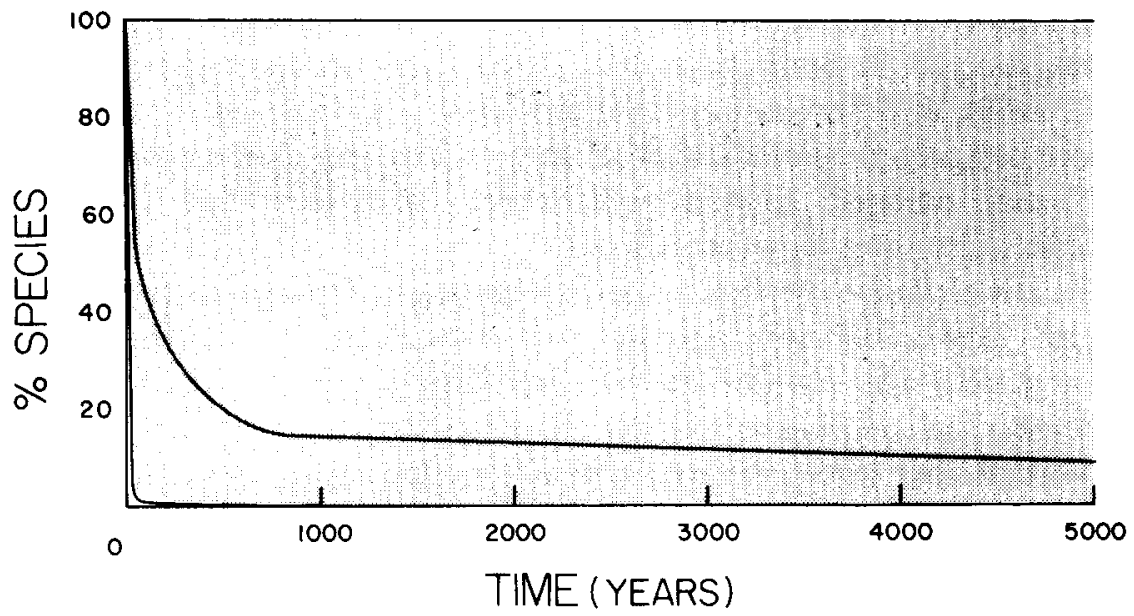

Fig. 5. The faunal collapse of the Nairobi National Park. The solid line represents the percentage species loss through time according to Soulé et al.'s (1979) Model 4. The stippled area represents a $95 \%$ simultaneous prediction interval.

Galli et al. (1976). The $95 \%$ prediction intervals for these models span \pm 5 and \pm 10 species respectively (Table 3 ).

The imprecision of these models confirms the contention that species number is inadequately modelled by area alone and suggests that the species-area relationship can only illustrate that species number generally increases with area.

\section{DISCUSSION}

The application of the species-area relationship to the design of nature reserves has been considered the 'crowning achievement' (Faaborg, 1979; Samson, 1980) of island biogeographic theory. However, these results indicate that the species-area relationship and models of faunal collapse are weak conservation principles; they have low explanatory power, are sensitive to particular cases, and give unreliable estimates. In addition to their predictive shortcomings, these models ignore species identity (Diamond, 1976), habitat heterogeneity (Abele \& Connor, 1979), and population sizes (Haila \& Jarvinen, 1981). More specific considerations of habitat requirements (MacArthur \& Wilson, 1967), minimum areas (Moore \& Hooper, 1975; Galli et al., 1976) and population sizes 
(Franklin, 1980; Haila \& Jarvinen, 1981), disturbance regimes (Pickett \& Thompson, 1978; Simberloff, 1982), social and economic constraints (Coe, 1980), and human impact (Spiridonov, 1979) will surely improve reserve design. The performance of species-area regressions and models of faunal collapse mandate that they be subordinate to these considerations in policy formulation.

The low explanatory power of area frustrates reliable prediction; it also suggests that equilibrium interpretations of species-area regressions are unwarranted. The equilibrium interpretation is that the regression line represents the equilibrium number of species for a given area, whereas, a strict statistical interpretation is that the line represents the average species number for a given area. For example, if an island lies above the species-area regression, the equilibrium interpretation is that the island is supersaturated and that it will eventually relax to its equilibrium number. The statistical interpretation is that the island has a positive error associated with it. This error may represent habitat heterogeneity, resource availability, or some other factor. The low explanatory power of area suggests that these other factors probably are important determinants of species diversity and that they cannot be ignored when interpreting a species-area regression.

Temple (1981) advocates inter-island transfers of endangered species to prevent their extinction. He presents many biological factors that support this policy but he also appeals to equilibrium theory as a justification. He identifies donor islands as those that lie above a species-area regression line; recipient islands lie below it. Donor islands will inevitably lose species as they relax to the equilibrium condition; recipient islands are impoverished and can therefore accommodate orphan species. Of course, it is necessary to assume that the displacements from the regression line represent actual perturbations from an equilibrium condition and not errors associated with habitat heterogeneity or resource availability. The performance of area in explaining species number cautions against this assumption. The biological considerations favouring inter-island transfers may be sound and justifiable but an appeal to equilibrium theory is clearly unnecessary and unwarranted.

We have demonstrated that species-area regressions and models of faunal collapse have little predictive value. Nevertheless, many ecologists (Terborgh, 1974, 1975; Soulé et al., 1979; Soulé, 1980) argue that poor prediction is better than no prediction at all. Soule (1980) writes in Conservation biology: 
... the luxuries of confidence limits and certainty are ones that conservation biologists cannot now afford, given the rate of habitat destruction documented in many of the chapters of this book. Constructive criticism is welcome, but to embrace the purist's motto of 'insufficient data' is to abandon the bleeding patient on the table. (p. 268)

We agree that the situation is serious, but we do not agree that the urgency of conservation makes demonstrably inadequate models acceptable. Soulé's contention of 'insufficient data' is valid if only area is considered in nature reserve design. Ecologists must shift their attention from area alone, and consider more specific autecological factors in the preservation of endangered species. The urgency of preserving natural diversity demands this.

\section{ACKNOWLEDGEMENTS}

We thank D. Simberloff, S. Mopper, D. Strong, P. Price, R. Fritz, C. Slobodchikoff, the FSU ecology group, the NAU ecology group, and an anonymous reviewer for insightful criticisms and suggestions.

\section{REFERENCES}

Abele, L. G. \& Connor, E. F. (1979). Application of island biogeography theory to refuge design: Making the right decision for the wrong reasons. In Proceedings of the first conference on scientific research in the national parks, I, ed. by R. M. Linn, 89-94. Washington, USDI.

Coe, M. (1980). African wildlife resources. In Conservation biology: an evolutionary-ecological perspective, ed. by M. E. Soulé and B. A. Wilcox, 273-302. Sunderland, Mass., Sinauer.

Connor, E. F. \& McCoy, E. D. (1979). The statistics and biology of the species area relationship. Am. Nat., 113, 791-833.

Diamond, J. M. (1972). Biogeographic kinetics: Estimation of the relaxation times for avifaunas of the southwest Pacific islands. Proc. natn. Acad. Sci. U.S.A., 69, 3199-203.

Diamond, J. M. (1975). The island dilemma: Lessons of modern biogeographic studies for the design of nature reserves. Biol. Conserv., 7, $129-46$.

Diamond, J. M. (1976). Island biogeography and conservation: Strategy and limitations. Science, N.Y., 193, 1027-9.

Diamond, J. M. \& May, R. M. (1976). Island biogeography and the design of nature reserves. In Theoretical ecology, ed. by R. M. May, 163-86. Philadelphia, Saunders. 
Diamond, J. M. \& Mayr, E. (1976). Species-area relation for birds of the Solomon Archipelago. Proc. natn. Acad. Sci. U.S.A., 73, 263-6.

Faaborg, J. (1979). Qualitative patterns of avian extinction on neotropical landbridge islands: Lessons for conservation. J. appl. Ecol., 16, 99-107.

Franklin, I. R. (1980). Evolutionary change in small populations. In Conservation biology: an evolutionary-ecological perspective, ed. by M. E. Soulé and B. A. Wilcox, 135-49. Sunderland, Mass., Sinauer.

Galli, A. E., Leck, C. F. \& Forman, R. T. T. (1976). Avian distributional patterns in forest islands of different sizes in central New Jersey. $A u k, 93,356-64$.

Gilbert, F. S. (1980). The equilibrium theory of island biogeography: Fact or fiction? J. Biogeogr., 7, 209-35.

Haila, Y. \& Jarvinen, O. (1981). The underexploited potential of quantitative bird censuses in insular ecology. In Estimating numbers of terrestrial birds, ed. by C. J. Ralph and J. M. Scott, Studies in Avian Biol., 6, 559-65.

Hass, P. H. (1975). Some comments on the use of the species-area curve. Am. Nat., 109, 371-3.

Johnson, M. P. \& Simberloff, D. S. (1974). Environmental determinants of island species numbers in the British Isles. J. Biogeogr., 1, 149-54.

Kitchener, D. J., Chapman, A., Dell, J., Muir, B. G. \& Palmer, M. (1980a). Lizard assemblage and reserve size and structure in the Western Australian wheatbelt - some implications for conservation. Biol. Conserv., 17, 25-61.

Kitchener, D. J., Chapman, A., Muir, B. G. \& Palmer, M. (1980b). The conservation value for mammals of reserves in the Western Australian wheatbelt. Biol. Conserv., 18, 179-207.

MacArthur, R. H. \& Wilson, E. O. (1967). The theory of island biogeography. Princeton NJ, Princeton University Press.

McCoy, E. D. \& Connor, E. F. (1976). Environmental determinants of island species number in the British Isles: A reconsideration. J. Biogeogr., 3, $381-2$.

Moore, N. W. \& Hooper, M. D. (1975). On the number of bird species in British woods. Biol. Conserv., 8, 239-50.

Pickett, S. T. A. \& Thompson, J. N. (1978). Patch dynamics and the design of nature reserves. Biol. Conserv., 13, 27-37.

Preston, F. W. (1962). The canonical distribution of commonness and rarity. Ecology, 43, 185-215.

Samson, F. B. (1980). Island biogeography and conservation of nongame birds. Trans. N. Am. Wildl. Nat Resour. Conf., 45th, 245-51.

Shreeve, T. G. \& Mason, C. F. (1980). The number of butterfly species in woodlands. Oecologia, 45, 414-18.

Simberloff, D. (1982). Big advantages of small refuges. Natural History, 91(4), 6-15.

Sokal, R. R. \& Rohlf, F. J. (1969). Biometry. San Francisco, Freeman.

Soulé, M. E. (1980). Thresholds for survival: Maintaining fitness and evolutionary potential. In Conservation biology: an evolutionary-ecological perspective, ed. by M. E. Soulé and B. A. Wilcox, 95-118. Sunderland, Mass., Sinauer. 
Soulé, M. E., Wilcox, B. A. \& Holtby, C. (1979). Benign neglect: A model of faunal collapse in the game reserves of East Africa. Biol. Conserv., 15, $259-72$.

Spiridonov, V. N. (1979). Change in species composition of the herbage in herb birch forest under the effect of recreational stress. Soviet J. Ecol., 9, 377-9.

Temple, S. A. (1981). Applied island biogeography and the conservation of endangered island birds in the Pacific Ocean. Biol. Conserv., 20, 147-61.

Terborgh, J. (1974). Preservation of natural diversity: The problem of extinction prone species. BioScience, 24, 715-22.

Terborgh, J. (1975). Faunal equilibria and the design of wildlife preserves. In Tropical ecological systems: trends in terrestrial and aquatic research, ed. by F. B. Golly and E. Medina, 369-80. New York, Springer-Verlag.

Ward, L. K. \& Lakhani, K. H. (1977). The conservation of juniper: The fauna of food-plant island sites in Southern England. J. appl. Ecol., 14, 121-35.

Weisberg, S. (1980). Applied linear regression. New York, Wiley.

Western, D. \& Ssemakula, J. (1981). The future of the savannah ecosystems: Ecological islands or faunal enclaves? African J. Ecol., 19, 7-20.

Wilcox, B. A. (1980). Insular ecology and conservation. In Conservation biology: an evolutionary-ecological perspective, ed. by M. E. Soulé and B. A. Wilcox, 95-117. Sunderland, Mass., Sinauer.

\section{APPENDIX 1}

(a) Influence functions

The slope and intercept estimates following the deletion of the i'th case are

$$
\hat{\mathbf{B}}_{0,-1}=\hat{\mathbf{B}}_{0}-\left[\left(\mathrm{E}_{\mathrm{i}} / \mathrm{n}\right)\left(\sum_{\mathrm{j}=1}^{\mathrm{N}} \mathrm{x}_{\mathrm{j}}^{2}-\mathrm{x}_{\mathrm{i}} \sum_{\mathrm{j}=1}^{\mathrm{N}} \mathrm{x}_{\mathrm{j}}\right)\right] /\left[\operatorname{SXX}\left(1-\mathrm{V}_{\mathrm{i}}\right)\right]
$$

and

$$
\hat{\mathbf{B}}_{1,-1}=\hat{\mathbf{B}}_{1}-\left[\left(\mathrm{E}_{\mathrm{i}} / \mathbf{n}\right)\left(\mathrm{x}_{\mathrm{i}}-\overline{\mathbf{x}}\right)\right] /\left[\mathbf{S X X}\left(1-\mathrm{V}_{\mathrm{i}}\right)\right]
$$

where,

$\hat{\mathbf{B}}_{0}=$ estimate of the intercept using all data

$\hat{\mathbf{B}}_{1}=$ estimate of the slope using all data

$E_{i}=y_{i}-\hat{B}_{0}-\hat{B}_{1} x_{i}$

SXX $=$ corrected sum of squares for the areas

$\mathrm{V}_{\mathrm{i}}=1 / \mathrm{n}+\left(\mathrm{X}_{\mathrm{i}}-\overline{\mathrm{x}}\right)^{2} / \mathrm{SXX}$

The value $E_{i}$ is the residual for the $i$ th case. 
(b) Confidence intervals

A $(1-\alpha) \times 100 \%$ confidence interval is given by

$$
\hat{\mathrm{y}} \pm \mathrm{t}_{(\alpha / 2), \mathrm{n}-2} \hat{\sigma}\left[1 / \mathrm{n}+(\mathrm{x}-\overline{\mathrm{x}})^{2} / \mathrm{SXX}\right]^{1 / 2}
$$

where, $\hat{y}$ is the point estimate, $t_{(\alpha / 2), n-2}$ is the appropriate value from the $t-$ distribution, and $\hat{\sigma}$ is the standard error of regression. $\mathrm{A}(1-\alpha) \times 100 \%$ simultaneous confidence is given by

$$
\hat{\mathrm{y}} \pm[2 \mathrm{~F}(\alpha, 2, \mathrm{n}-2)]^{1 / 2} \hat{\sigma}\left[1 / \mathrm{n}+(\mathrm{x}-\overline{\mathrm{x}})^{2} / \mathrm{SXX}\right]^{1 / 2}
$$

where, $F(\alpha, 2, n-2)$ is the appropriate value from the $F$-distribution with 2 degrees of freedom for the numerator and $n-2$ degrees of freedom for the denominator.

(c) Prediction intervals

A $(1-\alpha) \times 100 \%$ prediction interval is given by

$$
\hat{\mathrm{y}} \pm \mathrm{t}_{(\alpha / 2), \mathrm{n}-2} \hat{\sigma}\left[1+1 / \mathrm{n}+(\mathrm{x}-\overline{\mathrm{x}})^{2} / \mathrm{SXX}\right]^{1 / 2}
$$

where, $\hat{y}$ is the point estimate, $t_{(\alpha / 2), n-2}$ is the appropriate value from the $t-$ distribution, and $\hat{\sigma}$ is the standard error of regression. $\mathrm{A}(1-\alpha) \times 100 \%$ simultaneous prediction interval is given by

$$
\hat{\mathrm{y}} \pm[2 \mathrm{~F}(\alpha, 2, \mathrm{n}-2)]^{1 / 2} \hat{\sigma}\left[1+1 / \mathrm{n}+(\mathrm{x}-\overline{\mathrm{x}})^{2} / \mathrm{SXX}\right]^{1 / 2}
$$

where, $F(\alpha, 2, n-2)$ is the appropriate value from the $F$-distribution with 2 degrees of freedom for the numerator and $n-2$ degrees of freedom for the denominator.

(d) Inverse prediction intervals

The upper and lower bounds for a $(1-\alpha) \times 100 \%$ inverse prediction interval are

$$
\overline{\mathrm{x}}+\hat{\mathrm{B}}_{1}\left(\mathrm{y}_{\mathrm{i}}-\overline{\mathrm{y}}\right) / \mathrm{D} \pm\left(\mathrm{t}_{\alpha, \mathrm{n}-2} / \mathrm{D}\right) \hat{\sigma}\left[\mathrm{D}+\mathrm{D} / \mathrm{n}+\left(\mathrm{y}_{\mathrm{i}}-\overline{\mathrm{y}}\right)^{2} / \sum_{\mathrm{j}=1}^{\mathrm{N}} \mathrm{x}_{\mathrm{j}}^{2}\right]
$$

where,

and

$$
\mathrm{D}=\mathrm{F}(\alpha, 1, \mathrm{n}-2) \hat{\sigma}^{2}\left(1 / \mathrm{SXX}-1 / \sum_{\mathrm{j}=1}^{\mathrm{N}} \mathrm{x}_{\mathrm{j}}^{2}\right)
$$

$$
\hat{\mathbf{x}}_{\mathrm{i}}=\left(\mathrm{y}-\hat{\mathbf{B}}_{0}\right) / \hat{\mathbf{B}}_{1}
$$

$\hat{\mathbf{x}}_{\mathrm{i}}$ is the point estimate. 